\title{
ABDOME AGUDO PERFURATIVO / OBSTRUTIVO EM DECORRÊNCIA DE NEOPLASIA - UM RELATO DE CASO
}

\author{
ACUTE PERFORATORY/ OBSTRUCTIVE ABDMEN DUE NEOPLASIA - A CASE \\ REPORT
}

\author{
Matheus Ferreira de Freitas 1 \\ Juliana Carrilho De Castro Caixeta Ferreira ${ }^{2}$ \\ Mateus Maziero de Carvalho ${ }^{3}$ \\ Marcela Leite Tavares ${ }^{4}$ \\ Vladimir Tarcísio Delfino de Oliveira ${ }^{5}$
}

RESUMO: Trata-se de um relato de caso de paciente do sexo masculino, etilista e tabagista há 50 anos, hábitos relevantes para desenvolvimento de inúmeras patologias, que apresentou quadro de abdome agudo perfurativo, por lesão gástrica perfurada, sendo abordado cirurgicamente e detectado massa gástrica. Paciente após sessenta dias da abordagem, evolui com quadro de abdome agudo obstrutivo, sendo necessário rápida intervenção, devido à evolução desta patologia e da causa base de todo o quadro que o paciente apresentava, assim como possíveis complicações de uma obstrução como: supercrescimento bacteriano, colapso do segmento acometido, vômitos frequentes que exacerbam o distúrbio hidroeletrolítico resultando em hipocalemia e hipovolemia grave.

Palavra- chave: Cirurgia geral. Gastroenterologia. Neoplasia. Perfurativo. Obstrutivo.

\footnotetext{
${ }^{1}$ 6o ano do curso de Medicina - Universidade Brasil. E-mail: julianacarrilhocastro@hotmail.com.

${ }^{2}$ 6o ano do curso de Medicina - Universidade Brasil. E-mail: mafefrei@gmail.com.

3 Ensino Superior Completo - Universidade de Marília E-mail: mmaziero@hotmail.com.

4 Ensino Superior Completo - Faculdade Ceres E-mail: marcellaa_92@hotmail.com.

5 Orientador: Doutor, Professor, Preceptor e Médico Cirurgião - Universidade Brasil/Santa Casa de Misericórdia de Fernandópolis/SP. E-mail: dr.tarcisiooliveira@hotmail.com.
} 
ABSTRACT: This is a case report of a male patient, alcoholic and smoker for 50 years, relevant habits for the development of numerous pathologies, who presented with a perforating acute abdomen due to perforated gastric lesion, being surgically approached and gastric mass detected. Sixty days after the approach, the patient evolved with acute obstructive abdomen, requiring rapid intervention, due to the evolution of this pathology and the underlying cause of the entire condition that the patient had, as well as possible complications of an obstruction such as: bacterial overgrowth, collapse of the affected segment, frequent vomiting that exacerbate the hydroelectrolytic disorder resulting in hypokalemia and severe hypovolemia.

Keywords: General surgery. Gastroenterology. Neoplasm. Perforating. Obstructive.

\section{INTRODUÇÃO}

Abdome agudo obstrutivo é uma situação de emergência, na qual se encontra um fator obstrutivo responsável pelo exuberante quadro clínico. Apresenta gravidade variável e caráter evolutivo necessitando de uma rápida intervenção, na maioria dos casos sendo cirúrgica. Dentre as causas, são elas mecânicas: aderências/bridas, hérnias externas e carcinoma coloretal, seguido de doença diverticular, doença de crohn, intussuscepção, vólvulo de sigmóide e as raras que são tumor de intestino delgado, corpo estranho, bezoar, íleo biliar. E funcionais: como pós-operátorio, síndrome de Olgivie, opiáceos e anticolinérgicos, desordens metabólicas, entre outras. O quadro clínico é variável, depende do sítio e tempo de obstrução, presença ou não de complicações e grau de contaminação, habitualmente se caracteriza por dor abdominal em cólica, vômitos precoces, parada da eliminação de gases. Além disso, a clínica pode ser diferente se a obstrução intestinal for alta ou baixa. Ao exame físico, o paciente pode apresentar sinais de desidratação ou choque hipovolêmico, distensão abdominal central se obstrução alta e em flancos se obstrução baixa, peritonite e massas palpáveis. O diagnóstico normalmente pode ser feito por uma anamnese e exame físicos minuciosos e exames complementares auxiliam no diagnóstico diferencial, quando houver dúvidas, ou para diferenciar causa mecânica e funcional, bem como identificação de complicações. 


\section{OBJETIVO}

Relatar caso de abdome agudo obstrutivo em paciente do sexo masculino, 6I anos, diagnosticado em serviço de Cirurgia Geral em Fernandópolis-SP.

\section{RELATO DE EXPERIÊNCIA}

Paciente, sexo masculino, 6r anos, admitido no Serviço de Cirurgia Geral da Santa Casa de Fernandópolis-SP, em fevereiro de 2021, devido a um quadro de abdome agudo perfurativo, necessitando abordagem cirúrgica de emergência, na qual foi evidenciado uma lesão ulcerada perfurada de aproximadamente $2 \mathrm{~cm}$ em incisura angular, na ocasião foi realizado biópsia e rafia gástrica, paciente evolui com bom prognóstico e alta hospitalar sem nenhuma complicação. Em abril de 2021, paciente retorna ao mesmo Serviço de Cirurgia, com dor em epigástrio tipo cólica, de forte intensidade, de início progressivo, contínua, sem fator de melhora, acompanhado de náuseas, vômitos ( 3 episódios) há I dia. Após internação do paciente, em seu prontuário constava o resultado da biópsia de lesão gástrica, onde os achados histológicos eram fortemente sugestivos de adenocarcinoma. Paciente foi submetido a TC de abdome superior, sendo evidenciado sinais de oclusão e sub oclusão de intestino delgado com presença de níveis hidroaéreos, acúmulo de fezes em ampola retal, pequena quantidade de líquido livre na cavidade abdominal, imagem ovalada hipodensa posterior ao corpo do pâncreas, de origem indeterminada, nenhuma evidência de metástase. Realizada endoscopia digestiva alta, onde os resultados foram: em incisura angular, é possível observar úlcera grande, profunda, irregular, bordas elevadas e hiperemiadas, fundo necrótico e repleto de fibrina, medindo cerca de $4 \mathrm{~cm}$ de extensão. Devido ao resultado dos respectivos exames paciente foi submetido a cirurgia, no ato cirúrgico todo intestino delgado apresentava inúmeras bridas e aderências, sendo todas resolvidas. $\mathrm{O}$ tumor foi identificado em pequena curvatura, a conduta cirúrgica foi uma Gastrectomia Billroth II com Reconstrução do Trânsito em Y de Roux, necessário retirada do omento completo, gânglios e tumoração pancreática de aproximadamente $8 \mathrm{~cm}$, iniciado correção do trânsito há $40 \mathrm{~cm}$ do ângulo de Treitz, transmesocólica, fechamento do coto duodenal e fechamento do coto gástrico utilizando "anastomose 
oralis parcialis" terminolateral, com intenção de prevenir uma futura síndrome de dumping. Na parte distal, foi realizado êntero-êntero anastomose terminolateral. Paciente segue para leito de enfermaria 12 horas após procedimento, sem queixas.

\section{CONCLUSÃO}

Após abordagem cirúrgica devido quadro de abdome agudo perfurativo no qual a causa foi uma lesão gástrica fortemente sugestiva de adenocarcinoma, paciente evolui com abdome agudo obstrutivo, devido a bridas e aderências, no serviço de Cirurgia Geral da Santa Casa de Fernandópolis, após investigação do quadro do paciente a decisão foi abordagem cirúrgica para solucionar a origem da causa de toda clínica que o paciente apresentava, realizado Gastrectomia Billroth II com Reconstrução do Trânsito em Y de Roux modificada devido a anastomose gastrojejunal ser feita "oralis parcialis”. Paciente evolui com ruído hidro aéreo no segundo dia de pós-operatório, evacuação no quarto dia e alta hospitalar no sétimo dia, com alimentação sólida e sem nenhuma intercorrência ou complicação.

REFERÊNCIAS BIBLIOGRÁFICAS: Clínica cirúrgica. Vários autores. Hospital das clínicas FMUSP. Barueri, SP: Manole, 2008.

SABISTON. A base biológica da prática cirúrgica moderna. 19.ed. Saunders. Elsevier. MARGARIDO e TOLOSA. Técnica Cirúrgica Prática. Páginas 269-288. Atheneu, $200 I$.

https://www.scielo.br/scielo.php?script=sci_arttext\&pid=So104-42302005000100007 